\title{
American artisan cheese quality and spoilage: A survey of cheesemakers' concerns and needs
}

Megan N. Biango-Daniels* ${ }^{*}$ and Benjamin E. Wolfe
Biology Department, Tufts University, Medford, MA 02155

\section{ABSTRACT}

Production of artisan cheeses, including surfaceripened cheeses, has increased in the United States over the past 2 decades. Although many of these cheesemakers report unique quality and spoilage problems during production, a systematic assessment of the quality concerns facing this sector of specialty cheese production has not been conducted. Here we report the effects of microbial spoilage and quality issues on US artisan cheese production. In a survey of 61 cheesemakers, the most common issues reported were undesirable surface molds $(71 \%)$ and incorrect or unexpected colors or pigments on rinds (54\%). When asked, $18 \%$ of participants indicated that they were extremely concerned about quality and spoilage problems, and they indicated that their quality standards are frequently not met, either annually $(39 \%)$ or monthly (33\%). Although most of the respondents $(62 \%)$ said that just 0 to $5 \%$ of their cheese was lost or rendered less valuable due to quality issues annually, a small number (7\% combined) reported large losses of 20 to $30 \%$ or $>30 \%$ of their product lost or rendered less valuable. Almost all respondents (95\%) agreed that improved quality would reduce waste, increase profits, and improve production. The survey respondents indicated in open response questions that they want access to more online resources related to quality issues and digital forums to discuss issues with experts and peers when problems arise. These findings represent the first attempt to document and estimate the effect of quality and spoilage on the American artisan cheese industry. Future work should investigate what technologies, interventions, or information could reduce losses from these problems.

Key words: surface-ripened cheese, artisan cheese, spoilage, quality

Received July 23, 2020.

Accepted January 17, 2021.

*Corresponding author: Megan.Biango_Daniels@Tufts.edu

\section{INTRODUCTION}

There has been growth in the number of artisan cheesemakers in the United States over the past few decades (Dairy Farmers of Wisconsin, 2018). When describing cheese, the words "artisan" and "artisanal" mean that cheeses are produced traditionally, by hand, and in small batches, with as little mechanization as possible (D'Amico, 2017). Although cheese has been made in this manner for thousands of years (Fox and McSweeney, 2004), only recently has this style of cheesemaking regained popularity in the United States. Dairy farmers and cheesemakers have responded to the call for greater cheese variety, realizing the value added by these products (Paxson, 2012). The sales of these cheeses meet growing consumer demand for a broader range of flavors and have almost doubled in some regions (Dairy Farmers of Wisconsin, 2018).

Surface-ripened cheeses - including those with bloomy, washed, and natural rinds - are an important category of products that are increasing in the specialty cheese market. Bloomy rind cheeses, such as Camembert and Brie, are high moisture cheeses that are inoculated with specific bacterial and mold cultures during production that give them their characteristic softness and white color (Beresford and Williams, 2004; Parente and Cogan, 2004; Marcellino and Benson, 2014). Washed rind cheeses, such as Limburger and Gruyère, are repeatedly washed with a salt solution during aging. This creates a characteristic pink or orange pigmented biofilm on their rind (Beresford and Williams, 2004; Parente and Cogan, 2004). Natural rind cheeses, such as traditional blue cheeses and Tomme de Savoie, are usually neither disturbed nor manipulated during aging. This process leads to a thick, mottled, dry rind composed of molds, yeast, and bacteria present in the aging environment (Marcellino and Benson, 2014; Wolfe et al., 2014).

Although these 3 kinds of surface-ripened cheeses have different characteristics, they all have communities of microbes that originate from various sources including starter cultures, milk microbiota, and house microbiota (Ercolini et al., 2009; Bokulich and Mills, 
2013; Falardeau et al., 2019). During the aging process, the microbial community undergoes succession (Irlinger and Mounier, 2009; Ropars et al., 2012; Wolfe et al., 2014; Bassi et al., 2015; Macori and Cotter, 2018). Lactic acid bacteria dominate the microbial communities of the cheese curd, breaking down lipids and proteins, and making lactic acid and lactate from lactose (Irlinger and Mounier, 2009). This acidification makes way for acid-tolerant yeasts and molds, such as Debaryomyces hansenii and Geotrichum candidum, that develop the early stages of the rind on the curd surface. Fungal growth makes the rind less acidic, allowing less acidtolerant bacteria, such as various Proteobacteria and Actinobacteria species, to grow (Irlinger and Mounier, 2009). Secondary reactions such as fatty acid catabolism and amino acid catabolism by fungi and bacteria during the latter stages of community succession impart important flavors (McSweeney, 2004).

Most studies have focused on surface-ripened cheeses produced in Europe (Serhan et al., 2009; Fontana et al., 2010; Larpin-Laborde et al., 2011; Cogan et al., 2014; Ozturkoglu Budak et al., 2016). Only a handful of similar studies have included American surface-ripened cheeses from the United States or Canada, or their production and aging facilities (Bokulich and Mills, 2013; Banjara et al., 2015; Falardeau et al., 2019). The sharp contrast may be because surface-ripened cheeses are relatively new products in the United States, where the American Cheese Society (ACS; the largest professional association of artisan cheesemakers) is only 37 yr old (American Cheese Society, 2020a). The diversity of microbes and their good and bad quality attributes may not be the same across the United States and Europe due to differences in production practices and different distributions of beneficial and spoilage cheese microbes (Adams et al., 2013; Kivlin et al., 2014; Peay et al., 2016). Although more research, particularly in the United States, is needed, the growing body of information on the microbes associated with cheesemaking has the potential to help producers improve the quality and safety of products (Cocolin and Ercolini, 2015; Yeluri Jonnala et al., 2018).

Thus far, a large amount of research on surfaceripened cheese microbiology has focused on food safety and important concerns about human pathogens in cheeses (Gould et al., 2014; Jackson Choi et al., 2016; D'Amico, 2017; Jackson et al., 2018). Relatively little research has focused on quality issues of surface-ripened cheeses, which are often caused by undesirable bacteria and fungi (Garnier et al., 2017a,b; Kure and Skaar, 2019). Quality issues, also known as defects, include undesirable characteristics in flavor, texture or body, and appearance (Alvarez and Almena-Aliste, 2016).
Often "flavor" and "taste" are used interchangeably. However, taste includes only the 5 descriptors of salt, sweet, umami, sour, and bitter. Flavor is the complex effect of taste sensation, aromatic sensation of perception of volatile chemical compounds, and chemical feeling of substances in the mouth (Lahne, 2016; McCalman, 2016). Texture or body in cheese is detected through touch and sensation when breaking or chewing a piece of cheese. Descriptors of cheese texture include hardness, brittleness, stickiness, elasticity, and chewiness (Tunick, 2016). Appearance refers to how the finished cheese looks and how it matches expectations and standards. Food spoilage is deterioration, often caused by microbes, that leads to inedibility. Both quality problems and spoilage are important concerns. Product issues can lead to brand damage and profit losses, but they do not garner as much research as food safety (Snyder and Worobo, 2018).

The United States lacks critical baseline data on spoilage concerns and the economic effect of quality problems. This is especially true for surface-ripened cheeses with desirable microbial communities that are encouraged through affinage. It is unknown how widespread rind-related quality issues are, how concerned the cheesemakers are about them, and how frequently they cause cheesemakers to fail to meet their standards. Quality, profitability, and sustainability in the burgeoning American artisanal cheesemaking industry can only be improved by understanding these issues. The goals of this study were to assess the quality concerns of artisan cheesemakers in the United States making surface-ripened cheeses, to document some of the common issues encountered that are related to cheese rinds and the negative effects of these problems, and to understand what resources and tools are currently used as well as what additional tools and resources cheesemakers would find beneficial.

\section{MATERIALS AND METHODS}

\section{Questionnaire Tool Development}

Background communications and interactions with cheesemakers at the ACS meetings over the past $6 \mathrm{yr}$ were used to develop the survey. Anecdotal information about cheesemaking problems resulted from authors' participation in panels, scientific discussions at ACS meetings, and interactions with cheese guilds across the United States about the microbial diversity of surfaceripened cheeses. A draft of the survey was shared with individuals in the ACS Office of Marketing and Communication and industry experts, who provided feedback that was incorporated to improve the questions. 
The survey group was not exclusively cheesemakers that have cheeses with rinds. Eighty-two percent of the respondents made surface-ripened cheeses. In the survey, we first asked cheesemakers about quality concerns broadly, which included rind problems. Then, later in the survey, we asked specifically about rind-related issues that they experienced (Figure 1). Participants were asked whether they experienced quality concerns specifically related to the rinds of their cheeses, with a "not applicable" option for cheesemakers who do not make cheeses with rinds (Table 1). Many defects were listed that were in the broad categories of appearance,
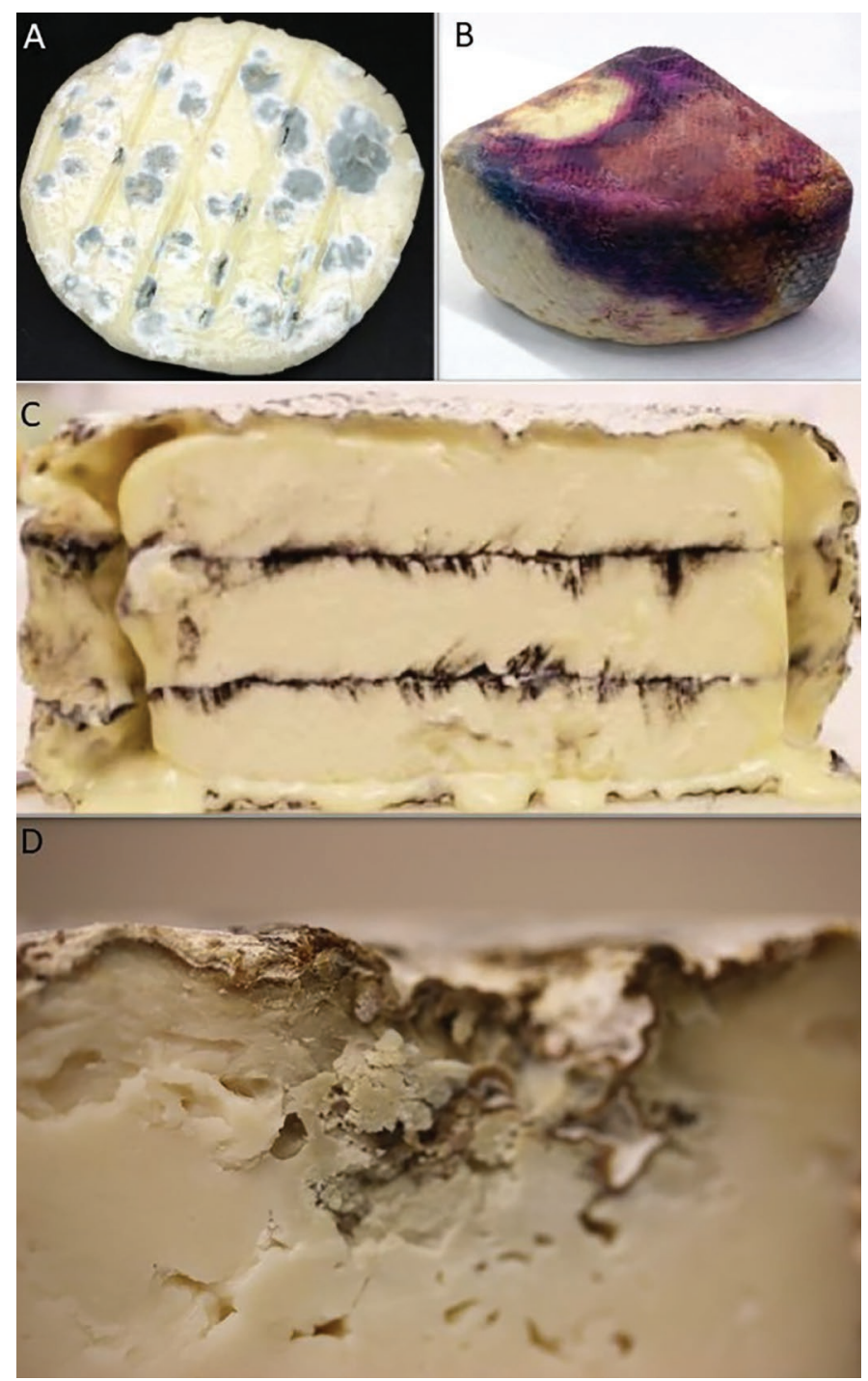

Figure 1. Examples of rind defects include (A) unwanted surface molds such as blue mold on Camembert cheese (photograph by B. E. Wolfe), (B) unwanted rind colors, such as purple rind defect (Kamelamela et al., 2018), (C) rind separation from paste in mold ripened cheese (Choi et al., 2016), and (D) unwanted divots or dimples in the rind (photograph by Biango-Daniels). rind structure and stability, and aroma and flavor. To encompass appearance-related defects, "incorrect or unexpected color or pigments" was included. It captured a variety of issues that could negatively affect rind appearance, but that could have resulted from unknown origins to cheesemakers. Due to prior work with cheesemakers that suggested undesirable surface molds are a frequent problem, participants were specifically asked if they had experienced this problem. Several defects were listed that related to rind structure and stability (Table 1). Participants were also asked if they had ever experienced unpleasant aromas, which is a category closely related to flavor-type defects (McCalman 2016). Additional rind issues included in the survey were unwanted divots or dimples and the related issue of undesirable internal molds, which can grow into the paste when rind damage is present.

A description of the study, including benefits provided with participation (none), and anticipated risks (low risk, equivalent to everyday internet use) were included on the first page of the survey. Questions were presented as either forced-choice (yes, no, or not applicable, as needed), selection from a Likert-type scale, or open fields for discursive responses. A question regarding the rind quality concerns encountered was presented as a list of possible issues. Participants were asked to select all that applied to their cheesemaking, and "not applicable" and "other" choices were provided. The 5-point ordinal Likert scales were used to measure respondents' attitudes regarding quality and spoilagerelated concerns. Participants were not required to evaluate every statement nor answer every question. The final version of the survey was developed using the online platform Wufoo (Supplemental Figure S1, https: //doi.org/10.6084/m9.figshare.13655984, Biango-Daniels and Wolfe, 2021). The survey and application for Institutional Review Board exemption were submitted to Tufts' Social, Behavioral, and Educational Research Institutional Research Board office. An exemption was granted on September 6, 2018.

\section{Administration of Survey}

To reach as many cheesemakers as possible, the survey was shared at national and regional levels. At the national level, the survey was made available to participants through a link embedded in the September 2018 CheeseBytes newsletter from the ACS, which was subscribed to by 1,689 cheesemakers and industry professionals. At a regional level, the survey link was embedded in newsletters from regional cheese guilds to their members. It was also shared with 144 individuals through an embedded link in an email sent directly to all US cheesemakers who were identified from the 
publicly available ACS media package of competitors in the 2018 annual competition and judging. A reminder email was sent to these listed competitors 1 mo after the initial email. Participation was voluntary, with no compensation offered. To protect anonymity, no identifying information was collected. Survey responses were received from 61 participants between September and December 2018.

\section{Data Analysis}

The responses were collected through the Wufoo user interface and exported in bulk to Excel (Microsoft Corporation). The data were visualized as frequency response or contingency tables. The data were further examined using descriptive tests (e.g., percent total of responses) to explore the quality concerns of American artisan cheese producers.

\section{RESULTS}

\section{Survey Group}

A series of questions asked at the beginning of the questionnaire aimed to describe the cheesemakers who participated in more detail. Participants were diverse in their location and the type or types and volume of cheese they produced annually. They were distributed across 21 states $(\mathrm{n}=61)$. The largest percentage of participants were from Maine and California, with $14.8 \%$ and $13.1 \%$ respectively. Four participants (6.5\%) chose not to identify their state.

Most of the participants indicated that they made multiple kinds of cheese, and $82 \%$ of respondents made 1 or more cheese with a rind. Only 11 of the 61 respondents made none of the following: "soft cheese (rennetset) with bloomy rind," "soft cheese (rennet-set) with washed rind," or "uncooked pressed (e.g., Cheddar)." Responses from all cheesemakers were analyzed, including those who had products without rinds, because there were "not applicable" or "other" options available for those producers to select in questions focused on rind specific problems. Sixty percent of the cheesemakers responded that they made a cooked pressed cheese (e.g., Alpine style), and 53\% indicated they made a soft cheese (rennet-set) with bloomy rind $(\mathrm{n}=61)$. Uncooked pressed cheese (e.g., Cheddar) was produced by $48 \%$ of participants $(\mathrm{n}=61)$. Both lactic (predominantly acid coagulation) and soft cheeses (rennet-set) with washed rinds were made by $45 \%$ of the participants $(n=61)$. A quarter of the participants responded that they made other types of cheese, such as Gouda-style, fresh mozzarella, fresh Ricotta-style, cheese spreads, Queso Oaxaca, and original products $(n=61)$. Original products may

Table 1. Rind defects included in our survey and brief descriptions

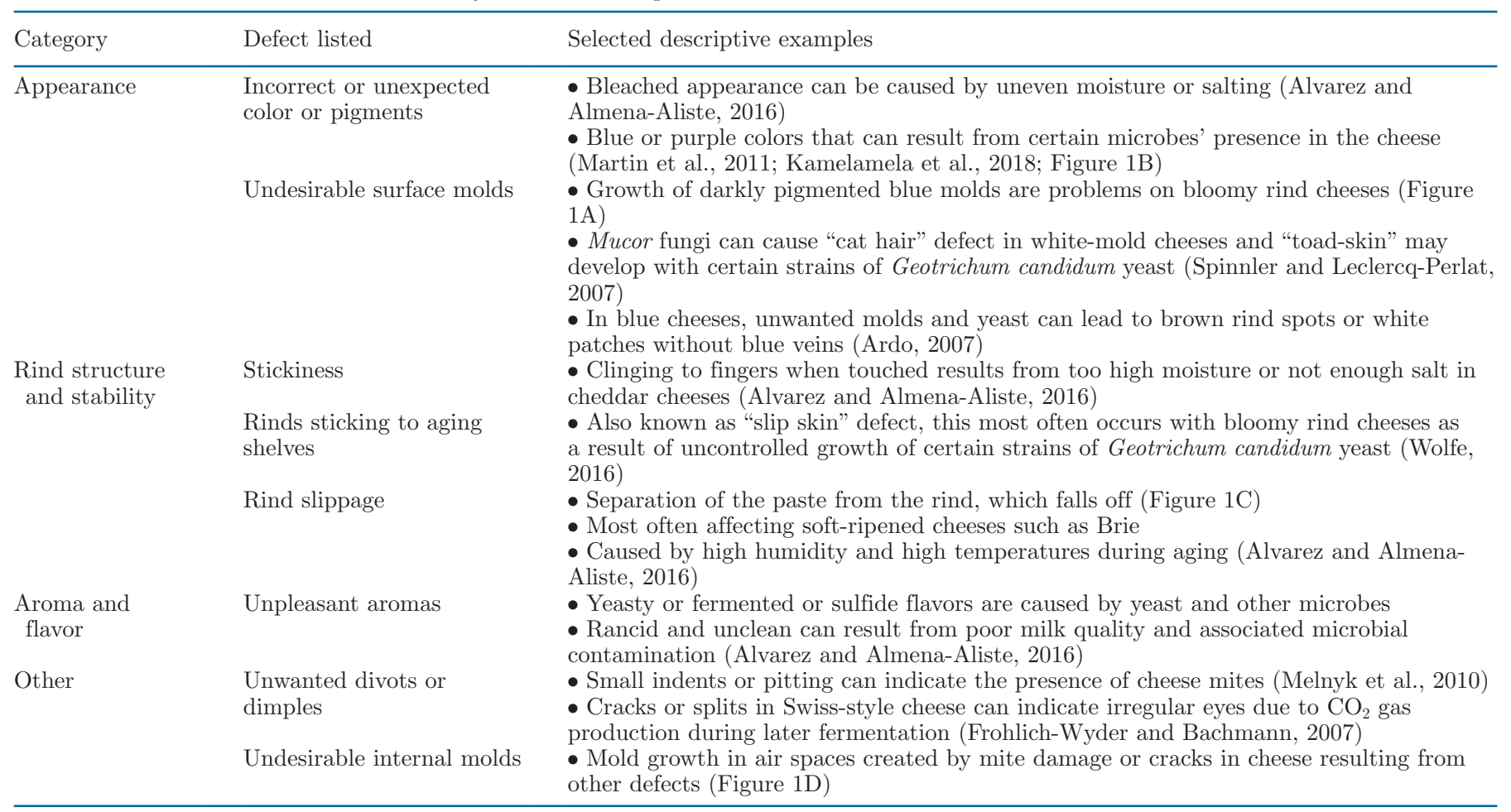


be new cheese types that are made with a combination of techniques that are not traditionally used together. In response to the question "How much cheese do you produce annually?" cheesemakers reported a range of production volumes $(\mathrm{n}=50)$ with an average amount produced of 122,928 lb and a median amount produced of 30,000 lb. Before determining the mean and median, we excluded 2 cheesemakers who produced more than 1 million pounds per year because they were outliers in terms of the volume produced. Of the respondents, 17 produced $<10,000 \mathrm{lb}$ per year, 18 produced 10,000 to $100,000 \mathrm{lb}$ per year, and 17 produced between 115,000 and $1,200,000 \mathrm{lb}$ per year $(\mathrm{n}=52)$.

\section{Most Important Cheese Rind Quality Problems}

When asked about general quality problems, cheesemakers were divided as to what the most important quality problems were; $56 \%$ and $54 \%$ of respondents indicated that consistency of flavor and consistency of texture were most important, respectively. However, between 20 and $31 \%$ of respondents also thought that cheese texture, the consistency of ripening speed, consistency of rind development, variability within a single batch, paste bitterness, or rind appearance were most important $(\mathrm{n}=61)$.

Most cheesemakers $(80 \%)$ responded that they were concerned about more than one of the possible rind quality concerns listed $(\mathrm{n}=59$; Table 2$)$. The top 2 rind issues respondents had experienced were undesirable surface molds $(71 \%)$ and incorrect or unexpected colors or pigments (54\%; Table 2). Those who responded that "other" rind quality concerns had been experienced shared that late blowing, the formation of larger than normal eyes, pockets, and even cracks, were an issue (Klijn et al., 1995). Some shared specific anecdotes about other problems that were not defined by a single category, such as "... a white mold that grows like barnacles on some of our cheeses... [that can] cause bitterness in the paste and rind," and additional textural issues such as "greasy rinds."

\section{Level of Concern, Frequency, and Occurrence of Quality Problems}

When survey participants were asked how concerning quality problems were to them using a Likert-type scale, $18 \%$ indicated that they were extremely concerned about these problems (Figure 2A). Three-quarters of combined participants' responses indicated that they were moderately $(48 \%)$ or slightly $(28 \%)$ concerned, and $7 \%$ of the participants said they were not at all concerned about quality problems in their cheesemaking $(\mathrm{n}=61)$.

Participants were asked to use a Likert-type scale to indicate how frequently their finished cheeses have had quality problems that caused them to fall below the standards that they hoped to achieve (Figure 2B). More than half of the participants indicated that quality standards were not met on either an annual (39\%) or monthly $(33 \%)$ basis $(\mathrm{n}=61)$. Quality standards were not met weekly by $3 \%$ of respondents. Roughly a quarter of participants (23\%) indicated that quality problems caused them to fall below their standards rarely, if ever, and $2 \%$ indicated that quality problems never caused them not to meet their standards (e.g., quality standards were always met).

Participants were asked to assess how widespread quality problems were using a Likert-type scale (Figure $2 \mathrm{C}$ ). A combined $41 \%$ of participants indicated that they either agreed or strongly agreed that not achieving quality standards was a widespread problem. Only $18 \%$ of participants combined either disagreed or strongly disagreed. However, $38 \%$ of the participants did not feel strongly that not achieving quality standards was a widespread problem, responding "neither agree or disagree" (Figure 2C). Two participants did not evaluate the statement $(\mathrm{n}=59)$.

Table 2. Percent of respondents who have experienced cheese rind-related quality concerns as self-reported $(\mathrm{n}=59)$

\begin{tabular}{lc}
\hline Have you ever experienced any of the following rind quality concerns? & "Yes" responses (\%) \\
\hline Undesirable surface molds (blue molds on bloomy rinds, Mucor; Figure 1A) & 71 \\
Incorrect or unexpected colors or pigments (Figure 1B) & 54 \\
Stickiness & 44 \\
Rind slippage & 42 \\
Rinds sticking to aging shelves or otherwise falling off (Figure 1C) & 32 \\
Unpleasant aromas & 29 \\
Undesirable internal molds & 24 \\
Unwanted divots or dimples (Figure 1D) & 22 \\
Not applicable & 10 \\
Other & 5 \\
\hline
\end{tabular}


A

$$
\begin{aligned}
& \text { How concerned are you about quality } \\
& \text { problems in your cheesemaking? } n=61
\end{aligned}
$$

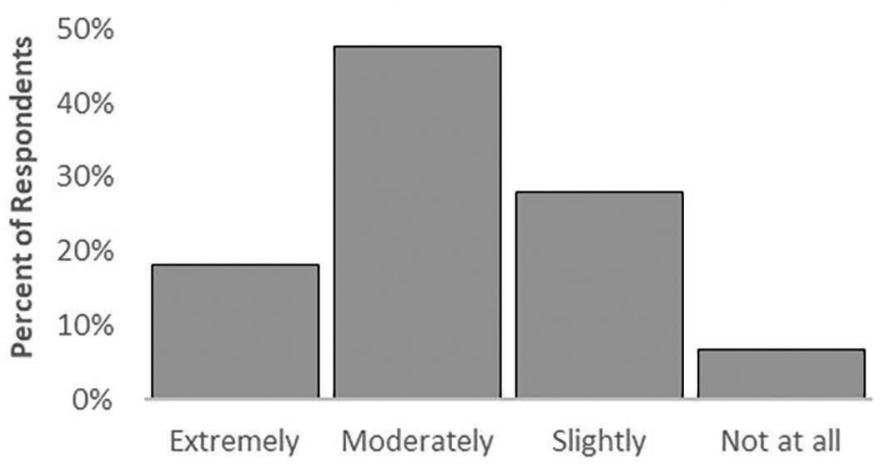

B How frequently do your finished cheeses have quality problems that make them fall below the standards

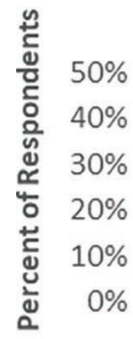

you hoped to achieve? $n=61$

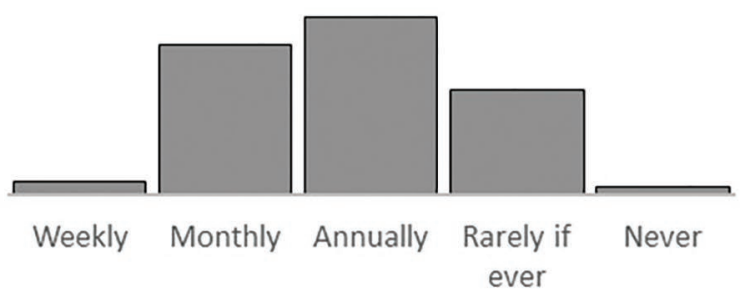

C

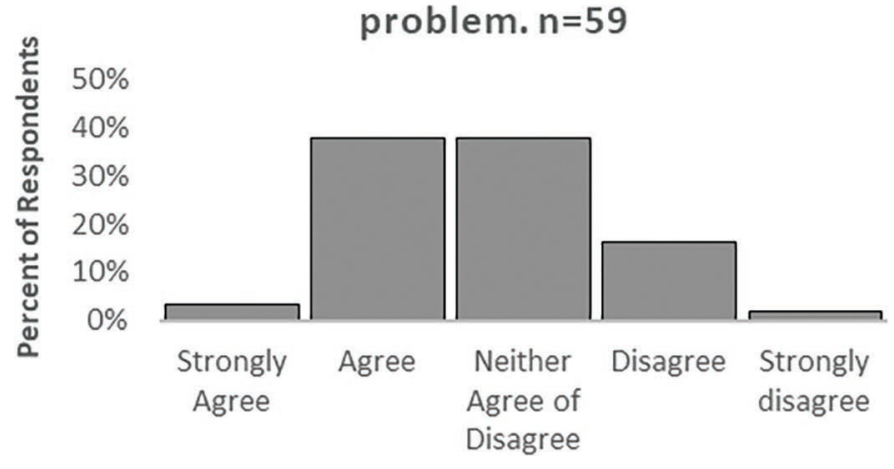

Figure 2. Self-reported level of concern, frequency, and cheesemakers' perceptions of how widespread quality issues are. Likert-type scale responses are reported as the percent of total respondents of each survey question.

\section{The Effect of Quality Issues on Profit}

The amount of product that is completely lost due to spoilage is not the only economically concerning factor because quality defects can render cheese less valuable.
A

In the past year, what percentage of your cheese was lost, or rendered less valuable, due to quality issues? $n=61$

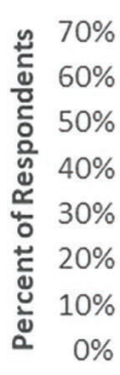

B

How much would improved cheese quality reduce your waste and increase your profits? $n=61$
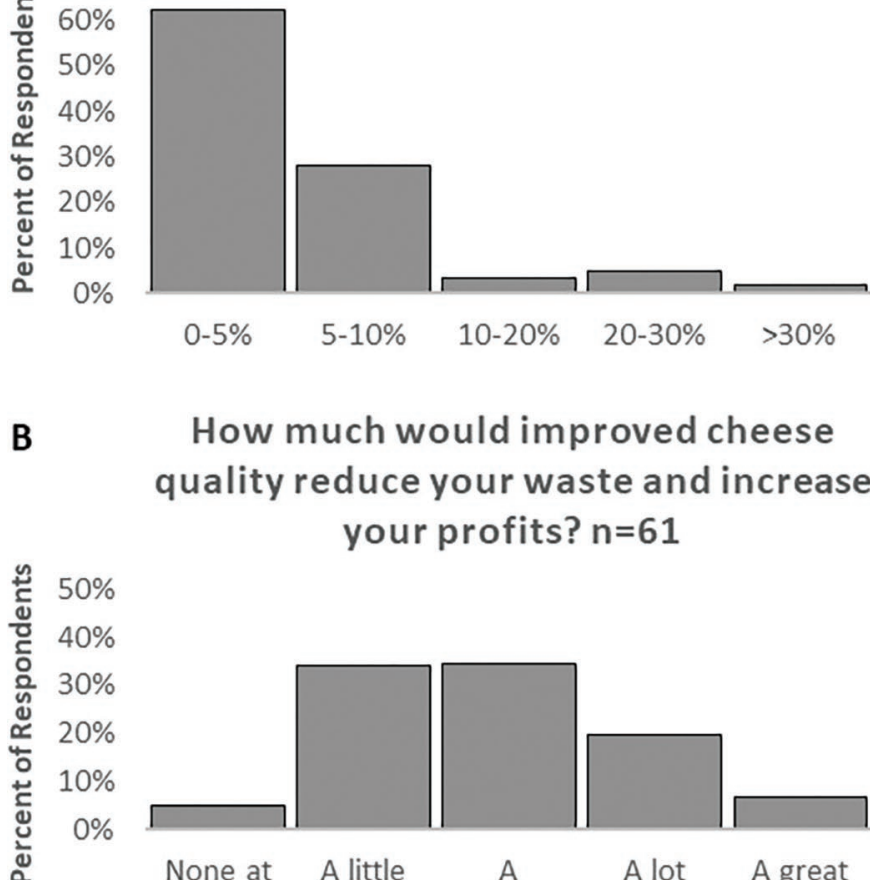

Figure 3. Self-reported impact of quality issues on profit. Likerttype scale responses are reported as the percent of total respondents of each survey question.

Using a Likert-type scale of annual percentage, $62 \%$ of respondents said that 0 to $5 \%$ of their cheese was lost or rendered less valuable because of quality issues in the last year (Figure 3A). Twenty-eight percent of the remaining respondents indicated that 5 to $10 \%$, and $3 \%$ of respondents indicated that 10 to $20 \%$, of their cheese was lost or rendered less valuable because of quality issues in the last year (Figure 3A). Of the combined respondents, $7 \%$ of cheesemakers said that $\geq 20 \%$ of their cheese was lost or rendered less valuable because of quality issues $(\mathrm{n}=61)$.

Despite the relatively small percentage of cheese that most cheesemakers self-reported as lost or rendered less valuable (Figure 3B), respondents indicated from a Likert-type scale that improved quality would reduce their waste and increase profits a great deal (7\%), a lot $(20 \%)$, or a moderate amount $(34 \% ; \mathrm{n}=61)$. Some respondents indicated that improved quality would only benefit them a little $(34 \%)$ or not at all $(5 \%)$ (Figure 3B). 
Table 3. Percent of respondents who have used specific tools or resources that are currently available to improve their cheese quality $(\mathrm{n}=61)$

\begin{tabular}{lc}
\hline $\begin{array}{l}\text { Do you use any of the following tools or resources to manage your } \\
\text { cheese quality? }\end{array}$ & "Yes" responses (\%) \\
\hline Scientific articles on spoilage or quality & 73.8 \\
In-person training & 68.9 \\
Online forums for cheesemakers & 57.4 \\
Diagnostic resources to identify spoilage microbes & 52.5 \\
Consultants & 50.8 \\
Online training & 34.4 \\
Blogs & 32.8 \\
Extension services & 31.1 \\
Podcasts & 9.8 \\
\hline
\end{tabular}

The economic impact of losing or having this much cheese rendered less valuable is difficult to estimate. By multiplying the pounds produced annually by each cheesemaker by the lowest and highest percentage in the range that they responded as lost or rendered less valuable, we can estimate that the average amount of cheese lost or rendered less valuable annually from all of the cheesemakers who responded was 1,918 to 7,022 $\mathrm{lb}(\mathrm{n}=52)$. Among the 17 small-scale producers who made $<10,000 \mathrm{lb}$ of cheese per year, 11 reported losing or having 0 to $5 \%$ rendered less valuable. Thus, the estimated average amount of cheese lost by these small-scale producers was 219 to $432 \mathrm{lb}$ annually ( $\mathrm{n}=$ 17). Cheesemakers who produced between 10,000 and $100,000 \mathrm{lb}$ annually $(\mathrm{n}=18)$ reported losing or having 5 to $10 \%$ rendered less valuable $(\mathrm{n}=9)$ or losing or having 0 to $5 \%$ rendered less valuable $(\mathrm{n}=8)$. Thus, the estimated average amount of cheese lost by these medium-scale producers is 1,485 to $2,594 \mathrm{lb}$ per year $(\mathrm{n}=18)$. There were 17 large-scale cheesemakers who made between 115,000 and 1.2 million $\mathrm{lb}$ per year. In this group, just 4 of these large producers reported losing or having 5 to $10 \%$ rendered less valuable. All other large producers reported losing or having rendered less valuable 0 to $5 \%$. The estimated average amount of cheese lost by these large-scale producers was 5,645 to 23,945 lb annually $(\mathrm{n}=17)$.

\section{Current Practices and Resources Used to Manage Quality Issues}

To better understand what tools and resources are already being used to manage cheese quality and prevent spoilage, respondents were asked to select what they used from a list of possible tools and resources. The most used resource indicated was scientific articles related to spoilage and quality with $73.8 \%$ of respondents (Table 3). More than half of the cheesemakers responded that they used in-person training (68.8\%), online forums for cheesemakers (57.4\%), diagnostic resources to identify spoilage microbes (57.4\%), and consultants $(50.8 \%)$ to manage cheese quality and spoilage. Tools used by approximately a third or less of the cheesemakers who responded included extension services and digital tools, such as online training, blogs, and podcasts (Table 3 ).

\section{Additional Resources Are Needed}

Most respondents indicated that they either strongly agreed $(36 \%)$ or agreed $(52 \%)$ that cheesemakers need additional resources to help address quality issues (Figure 4). Among respondents, $8 \%$ were neutral, and a combined $4 \%$ disagreed or strongly disagreed with the statement provided (e.g., cheesemakers do not need additional resources to address quality issues; $\mathrm{n}=61$ ).

Participants who responded to the open-ended question "What tools, resources, and/or knowledge would help you improve cheese quality"? $(\mathrm{n}=42)$ shared many different ideas of what would be helpful. Cheesemakers' responses showed a desire for better communication. One major idea that appeared to be shared by many

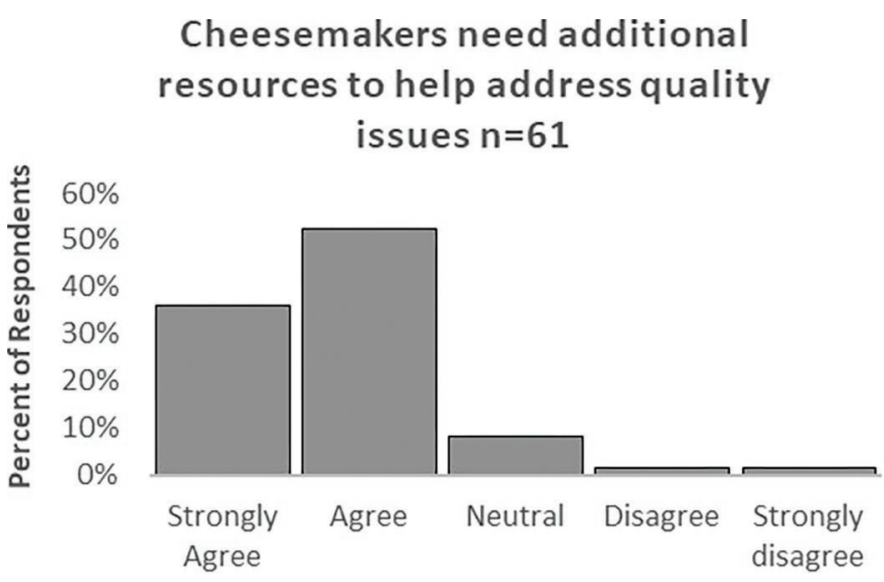

Figure 4. Self-reported desire of cheesemakers for additional resources to address quality issues. Results are reported as the percent of total respondents based on a Likert-type scale. 
cheesemakers who responded was that they wanted more online resources. Ideas included digital forums and online resources that facilitate open discussion of issues and help them find science-based solutions, respectively. One responder who articulated their desire for forums and resources said they would like "more open online or in-person forums for cheesemakers to discuss issues they may be having and how they are working to solve them...[and]... more readily available and easily found scientific resources (online)." Another similar response was "I wish there were more online tools available. In other areas of our farm, there are plenty of online resources for us to troubleshoot and find answers to problems. I find it VERY difficult to get help online, or to find information online with regard to small-scale cheese making..."

Some respondents were more specific to the kind of forum and access to information and resources that they wanted. They asked for a digital space where scientific and technical experts in cheese can engage with them directly. One respondent said that they want "an online portal where we upload photos and post questions and concerns, and get feedback from actual professionals (not just random folks who think they know)." Another respondent said that "our staff often says how useful it would be to have an online forum for professional cheesemakers and technical experts."

\section{DISCUSSION}

Quality and spoilage issues are concerning to many US artisan cheese producers according to our survey. Cheesemakers regularly encounter problems that make their finished cheeses fall below the quality standards they hoped to achieve. The top 4 quality issues reported related to rinds are undesirable surface molds, incorrect or unexpected colors or pigments, stickiness, and rind slippage. It was surprising that most respondents said that a small amount $(0-5 \%)$ of their cheese was lost, or rendered less valuable, because of quality issues in that last year. The number expected could have been higher, given the limited resources that are available to artisan cheese producers around quality issues. However, 7\% of cheesemakers indicated that a large amount of their cheese $(\geq 20 \%)$ was lost or rendered less valuable due to these issues. Controlling defects is important for their retail values because consumers are known to reject other products, such as so-called "ugly fruit," based on suboptimal appearance (Aschemann-Witzel et al., 2015; de Hooge et al., 2017). Additional research into rind defects would help improve quality and benefit producers by both increasing their profits on high-quality cheeses and reducing out-right losses.
One interesting observation from our data is that cheesemakers, as a group, are unsure about how widespread quality issues are, but strongly agree that additional resources to help address quality issues would benefit them personally. Although many agreed that not achieving expected quality standards was a widespread problem, almost as many said they neither agreed nor disagreed with that statement. This may be because the perceived severity of defects is based on many factors, including where and what kind of cheese is being made and sold, and consumers' expectations for certain cheeses. Another important factor that may explain this apparent contradiction is that cheesemakers' access to resources is unequal.

Extension services were used by less than a third of respondents. Extension services and other resources offered through land-grant institutions are clustered in states with large dairy industries (Table 4). Producers in other parts of the United States may not have access to any local assistance through extension services. The resources that respondents reported using may reflect these regional differences in extension support and the specific needs and issues of their production system. For example, training and short courses are offered on an annual basis at some institutions, including the Center for Dairy Research at the University of Wisconsin, Madison. These in-person trainings are a popular resource used by cheesemakers. Cheesemakers outside of these regions may be unaware that many extension or trade groups classes can be accessed online. Future work should survey cheesemakers to determine how aware they are of specific extension and trade resources that are available, such as those listed in Table 4.

How to clearly communicate available resources is an overarching problem for cheesemakers, as there is no clear directory to all services and trainings available across regions and states. Groups such as the National Dairy Council and the National Dairy Foods Research Centers and Applications Labs have attempted to organize this information for cheesemakers, publishing detailed reports and providing useful guides to resources for cheese quality and spoilage issues (National Dairy Council 2017). Specific resources, such as diagnostic testing through university dairy extension faculty and staff, may be available, but can be difficult to locate. However, services are not generally available to diagnose quality issues in surface-ripened cheeses that have different microbes living together in a community. Most services are tailored to identify specific pathogens or spoilage microbes. Furthermore, when diagnostic services are available through land-grant schools or large dairy programs, cheesemakers may not want to, or be able to, pay for tests. 
Table 4. Examples of some of the resources that are available for US artisan cheesemakers through dairy extension and other organizations

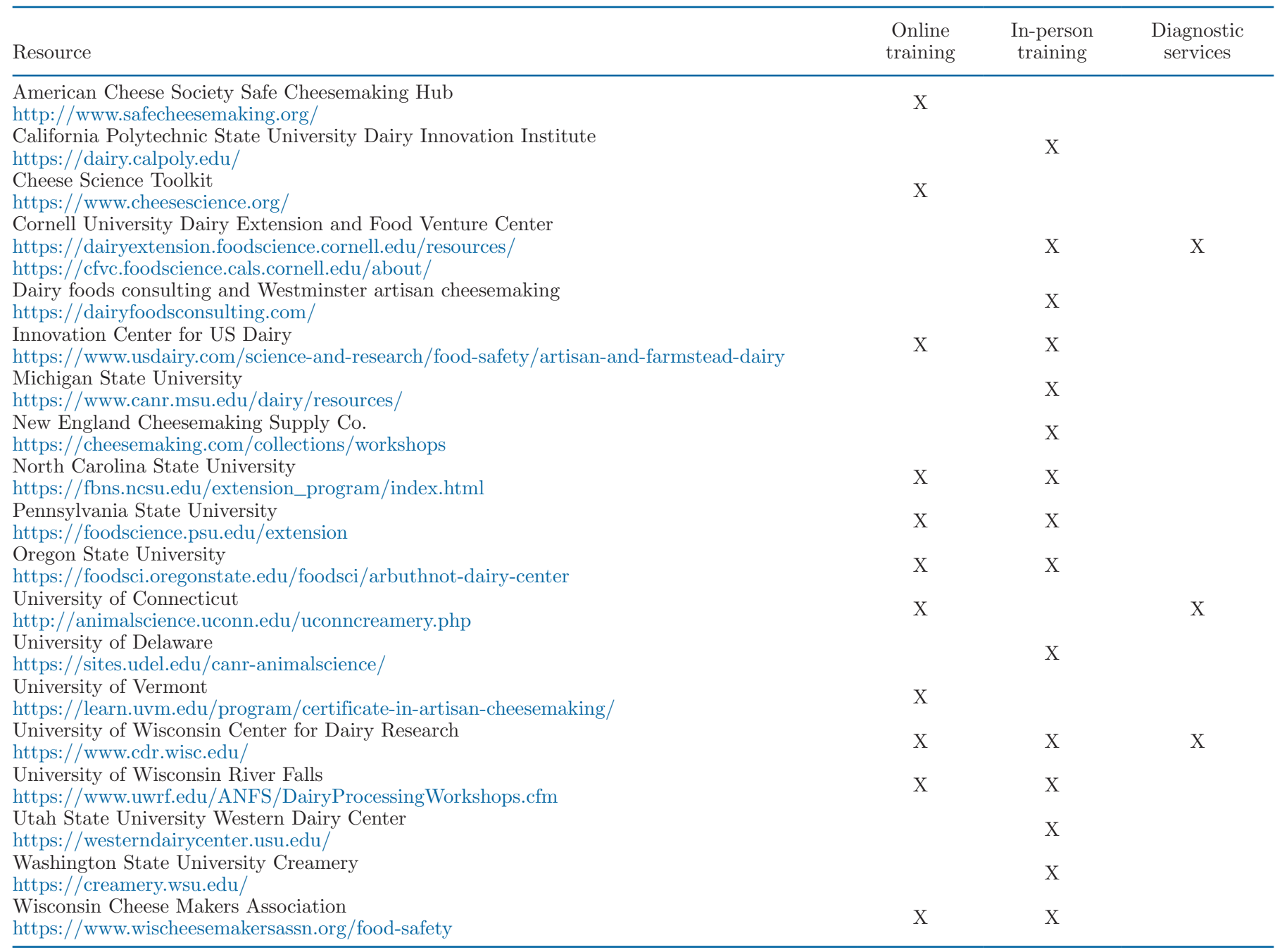

Cheesemakers indicated that popular resources are scientific articles and online forums. One place where they may find scientific articles and other press around cheese is in the Zotero database (https://www.zotero .org/groups/828463/cheesesociety/library), which is accessible to ACS members. However, this database is intended to support ACS members studying to become certified cheese professionals or sensory evaluators, not cheesemakers with quality or spoilage issues, and it does often not provide full articles unless they are open access. One way to remove the current paywall barriers to accessing scientific research of interest to cheesemakers and make information more easily understood is for scientists and scholars to write short summaries of findings online through blogs. One example of a blog that does this can be found on the website microbialfoods.org in the "Science Digested" section, which "...provides concise summaries of important research on microbial foods... these summaries emphasize the practical implications of the findings." This particular website is not specific to cheese and includes other fermented foods. Similarly, even though there are blogs specifically about cheesemaking, most are by enthusiasts, and few are educational resources. One of the few websites with educational blogs targeted to cheesemakers is cheesescience.com (Table 4), and it even offers an online class in collaboration with the Vermont cheese council. Another way that scientist and industry experts currently communicate is through popular online forums (Cheese Forum, 2020). However, to our knowledge, no forums are professionally moderated, and there are no scientists or technical experts contributing to cheesemaking forums.

Resources that were used by less than half of the respondents (Table 3) included digital resources such as online training, blogs, and podcasts. There is a growing number of online short courses that have been created by dairy extension experts as well as training 
materials (Table 4). Of the numerous resources that are currently available, most are focused on regulations, food safety plans, or product development (Table 4). For example, the ACS Safe Cheesemaking Hub contains an organized compendium of different safety resources (American Cheese Society 2020b). There are blogs and podcasts about cheese that are mostly entertaining. To our knowledge, there are none that have consistent resources on cheese science, safety, or quality (Kirkwood 2018). Expanding all types of digital resources to focus on artisan cheese could help reach cheesemakers with quality issues. To develop effective online resources, scientists will need to communicate outside of the normal channels of academia, including collaborating with trade groups and extension experts. To reach cheesemakers, academics should pursue speaking opportunities at the ACS annual meetings and with regional guilds. Furthermore, scientists should build relationships with extension agents and collaborate with them to write accessible summaries of their work with an emphasis on its impact to on the industry. These could be shared online and in newsletters directly to cheesemakers.

Beyond strengthening existing communication so that information reaches cheesemakers, additional online resources are desired by cheesemakers who want varied resources specifically for managing quality issues. Based on the responses of what type of resources cheesemakers would like more of, digital resources may be an emerging space for communications. Online blogs and frequently asked questions about artisan cheeses and short videos could reach more people and fill information gaps for those producers in regions without strong extension services. Furthermore, many referenced the need for an online space where cheesemakers can easily access and consolidate resources, such as scientific publications related to cheese quality, and training opportunities.

Several also indicated that they want an online forum to let them interact and ask questions directly of technical and scientific experts and communicate with other cheesemakers. It is easy to imagine a future online forum in which relevant scientific articles and trainings are centralized, and communication with technical experts and scientists is possible. Perhaps, such a space would allow cheesemakers to engage in lively discussion boards and collectively solve problem. However, it is also easy to see the hurdles to the creation of such a forum. Namely, who, or what, could build and manage it? Its creation would undoubtedly raise issues of privacy, anonymity, and profit. If the forum was privately run for profit, could revenue be generated while keeping cost to cheesemakers accessible, and would information shared be biased, reflecting adver- tisements or interests of that company and would ideas exchanged be copyrighted? One possible outcome could be that a professional group could develop this kind of resource and promote problem-solving with input from technical and scientific experts who are members. Alternatively, cheesemakers may self-organize, as has been the case with other groups in readily available social media platforms, such as Facebook (https://www .facebook.com). It is also possible that the demand for resources may become so great that entrepreneurs find a way to capitalize, creating a subscription-based site or one that is funded with advertisements or sponsors. Regardless of the form this interactive forum would take, important outstanding questions remain; namely, who would be selected as the "expert," and how would they be vetted and incentivized to participate in these forums? Regardless of what these future resources will look like, it's important that cheesemakers budget for professional development, organizational membership, and continuing education (training online or in-person) in their business plans so that they can afford to invest in the resources that enable production of safe, highquality cheese.

The growing US artisan cheesemaking industry will require additional resources moving forward that address not only safety, but also quality and spoilage concerns. Looking to the future, these resources used will evolve to fit the community's needs. Professional societies and extension services may be challenged to meet cheesemakers' needs and their desire for online resources. Addressing concerns of cheesemakers will remain challenging because of resource and tool development bottlenecks, the relatively few scientists that currently study these issues, and the limited funding sources available for this type of research.

\section{ACKNOWLEDGMENTS}

We thank Bronwen Percival of Neal's Yard Dairy, and Rebecca Orozco and Sarah Spira of the American Cheese Society (ACS) for their help developing survey questions. We appreciate the help of the ACS, who shared the survey with its members. We sincerely appreciate ACS members and members of cheese guilds nationwide who participated in our survey. This manuscript was supported by a grant from the USDA Northeast Dairy Business Innovation Center (Grant \#02200-DBIC-21-02, Montpelier, VT). The authors state there are no conflicts of interest.

\section{REFERENCES}

Adams, R. I., M. Miletto, J. W. Taylor, and T. D. Bruns. 2013. Dispersal in microbes: Fungi in indoor air are dominated by outdoor air 
and show dispersal limitation at short distances. ISME J. 7:12621273. https://doi.org/10.1038/ismej.2013.28.

Alvarez, V. B., and M. Almena-Aliste. 2016. Defects. Pages 222-226 in The Oxford Companion to Cheese. C.W. Donnelly, ed. Oxford University Press.

American Cheese Society. 2020a. History and Archives. Accessed Jul. 5, 2020. https://www.cheesesociety.org/about-us/history/.

American Cheese Society. 2020b. The Safe Cheesemaking Hub. Accessed Jul. 5, 2020. http://guides.cheesesociety.org/ safecheesemakinghub/gettingstarted.

Ardo, Y. 2007. Blue cheese. Pages 284-288 in Cheese Problems Solved. P. L. H. McSweeney, ed. Elsevier.

Aschemann-Witzel, J., I. de Hooge, P. Amani, T. Bech-Larsen, and M. Oostindjer. 2015. Consumer-related food waste: Causes and potential for action. Sustainability 7:6457-6477. https://doi.org/ $10.3390 /$ su7066457.

Banjara, N., M. J. Suhr, and H. E. Hallen-Adams. 2015. Diversity of yeast and mold species from a variety of cheese types. Curr. Microbiol. 70:792-800. https://doi.org/10.1007/s00284-015-0790-1.

Bassi, D., E. Puglisi, and P. S. Cocconcelli. 2015. Comparing natural and selected starter cultures in meat and cheese fermentations. Curr. Opin. Food Sci. 2:118-122. https://doi.org/10.1016/j.cofs .2015.03.002.

Beresford, T., and A. Williams. 2004. The microbiology of cheese ripening. Pages 287-317 in Cheese: Chemistry Physics And Microbiology, Volume 1 General Aspects. P. F. Fox, et al., ed. Elsevier.

Biango-Daniels, M., and B. Wolfe. 2021. Supplemental figure for "American artisan cheese quality and spoilage: A survey of cheesemakers' concerns and needs." https://doi.org/10.6084/m9.figshare .13655984.v2.

Bokulich, N. A., and D. A. Mills. 2013. Facility-specific "house" microbiome drives microbial landscapes of artisan cheesemaking plants. Appl. Environ. Microbiol. 79:5214-5223. https://doi.org/10.1128/ AEM.00934-13.

Cheese Forum. 2020. Accessed Jul. 5, 2020. http://cheeseforum.org/ articles/.

Choi, K. H., H. Lee, S. Lee, S. Kim, and Y. Yoon. 2016. Cheese microbial risk assessments - A review. Asian-Australasian. J. Anim. Sci. 29:307-314. https://doi.org/10.5713/ajas.15.0332.

Cocolin, L., and D. Ercolini. 2015. Zooming into food-associated microbial consortia: A "cultural" evolution. Curr. Opin. Food Sci. 2:43-50. https://doi.org/10.1016/j.cofs.2015.01.003.

Cogan, T. M., S. Goerges, R. Gelsomino, S. Larpin, M. Hohenegger, N. Bora, E. Jamet, M. C. Rea, J. Mounier, M. Vancanneyt, and M. Guéguen. 2014. Biodiversity of the surface microbial consortia from Limburger, Reblochon, Livarot, Tilsit, and Gubbeen cheeses. Pages 219-250 in Cheese and Microbes. C. W. Donnelly, ed. ASM Press.

D'Amico, D. J. 2017. Recommendations and outcomes from the first artisan cheese food safety forum. Food Prot. Trends 37:332-339.

Dairy Farmers of Wisconsin. 2018. Cheese Statistics. Accessed Jul. 5, 2020. https://www.wisconsincheese.com/media/facts-stats/cheese -statistics.

de Hooge, I. E., M. Oostindjer, J. Aschemann-Witzel, A. Normann, S. M. Loose, and V. L. Almli. 2017. This apple is too ugly for me!: Consumer preferences for suboptimal food products in the supermarket and at home. Food Qual. Prefer. 56:80-92. https:// doi.org/10.1016/j.foodqual.2016.09.012.

Ercolini, D., F. Russo, A. Nasi, P. Ferranti, and F. Villani. 2009. Mesophilic and psychrotrophic bacteria from meat and their spoilage potential in vitro and in beef. Appl. Environ. Microbiol. 75:19902001. https://doi.org/10.1128/AEM.02762-08.

Falardeau, J., K. Keeney, A. Trmčić, D. Kitts, and S. Wang. 2019. Farm-to-fork profiling of bacterial communities associated with an artisan cheese production facility. Food Microbiol. 83:48-58. https: //doi.org/10.1016/j.fm.2019.04.002.

Fontana, C., F. Cappa, A. Rebecchi, and P. S. Cocconcelli. 2010. Surface microbiota analysis of Taleggio, Gorgonzola, Casera, Scimudin and Formaggio di Fossa Italian cheeses. Int. J. Food Microbiol. 138:205-211. https://doi.org/10.1016/j.ijfoodmicro.2010.01.017.
Fox, P. F., and P. L. H. McSweeney. 2004. Cheese: An Overview. Pages 1-18 in Cheese: Chemistry Physics And Microbiology, Volume 1 General Aspects. P. F. Fox, et al., ed. Elsevier.

Frohlich-Wyder, M. T., and H. P. Bachmann. 2007. Swiss cheese. Pages 252-253 in Cheese Problems Solved. P. L. H. McSweeney, ed. Elsevier.

Garnier, L., F. Valence, and J. Mounier. 2017a. Diversity and control of spoilage fungi in dairy products: An update. Microorganisms 5:42. https://doi.org/10.3390/microorganisms5030042.

Garnier, L., F. Valence, A. Pawtowski, L. Auhustsinava-Galerne, N. Frotté, R. Baroncelli, F. Deniel, E. Coton, and J. Mounier. 2017b. Diversity of spoilage fungi associated with various French dairy products. Int. J. Food Microbiol. 241:191-197. https://doi.org/10 .1016/j.ijfoodmicro.2016.10.026.

Gould, L. H., E. Mungai, and C. Barton Behravesh. 2014. Outbreaks attributed to cheese: Differences between outbreaks caused by unpasteurized and pasteurized dairy products, United States, 1998-2011. Foodborne Pathog. Dis. 11:545-551. https://doi.org/ 10.1089/fpd.2013.1650.

Irlinger, F., and J. Mounier. 2009. Microbial interactions in cheese: Implications for cheese quality and safety. Curr. Opin. Biotechnol. 20:142-148. https://doi.org/10.1016/j.copbio.2009.02.016.

Jackson, K. A., L. H. Gould, J. C. Hunter, Z. Kucerova, and B. Jackson. 2018. Listeriosis outbreaks associated with soft cheeses, United States, 1998-2014. Emerg. Infect. Dis. 24:1116-1118. https:// doi.org/10.3201/eid2406.171051.

Kamelamela, N., M. Zalesne, J. Morimoto, A. Robbat, and B. E. Wolfe. 2018. Indigo- and indirubin-producing strains of Proteus and Psychrobacter are associated with purple rind defect in a surface-ripened cheese. Food Microbiol. 76:543-552. https://doi.org/ 10.1016/j.fm.2018.07.011.

Kirkwood, K. 2018. The 10 Best Podcast Episodes About Cheese. Culture Magazine. Accessed Nov. 10, 2019. https://culturecheesemag .com/article/10-best-podcast-episodes-about-cheese.

Kivlin, S. N., G. C. Winston, M. L. Goulden, and K. K. Treseder. 2014. Environmental filtering affects soil fungal community composition more than dispersal limitation at regional scales. Fungal Ecol. 12:14-25. https://doi.org/10.1016/j.funeco.2014.04.004.

Klijn, N., F. F. J. Nieuwenhof, J. D. Hoolwerf, C. B. Van der Waals, and A. H. Weerkamp. 1995. Identification of Clostridium tyrobutyricum as the causative agent of late blowing in cheese by speciesspecific PCR amplification. Appl. Environ. Microbiol. 61:29192924. https://doi.org/10.1128/AEM.61.8.2919-2924.1995.

Kure, C. F., and I. Skaar. 2019. The fungal problem in cheese industry. Curr. Opin. Food Sci. 29:14-19. https://doi.org/10.1016/j.cofs 2019.07.003.

Lahne, J. 2016. Flavor. Pages 698-700 in The Oxford Companion to Cheese. C.W. Donnelly, ed. Oxford University Press.

Larpin-Laborde, S., M. Imran, C. Bonaiti, N. Bora, R. Gelsomino, S. Goerges, F. Irlinger, M. Goodfellow, A. C. Ward, M. Vancanneyt, J. Swings, S. Scherer, M. Guéguen, and N. Desmasures. 2011. Surface microbial consortia from Livarot, a French smear-ripened cheese. Can. J. Microbiol. 57:651-660. https://doi.org/10.1139/ w11-050.

Macori, G., and P. D. Cotter. 2018. Novel insights into the microbiology of fermented dairy foods. Curr. Opin. Biotechnol. 49:172-178. https://doi.org/10.1016/j.copbio.2017.09.002.

Marcellino, S. N. O. S. B., and D. R. Benson. 2014. The good, the bad, and the ugly: Tales of mold-ripened cheese. Pages 95-131 in Cheese and Microbes. C. W. Donnelly, ed. ASM Press.

Martin, N. H., S. C. Murphy, R. D. Ralyea, M. Wiedmann, and K. J. Boor. 2011. When cheese gets the blues: Pseudomonas fluorescens as the causative agent of cheese spoilage. J. Dairy Sci. 94:31763183. https://doi.org/10.3168/jds.2011-4312.

McCalman, M. 2016. Flavor. Pages 274-277 in The Oxford Companion to Cheese. C. W. Donnelly, ed. Oxford University Press.

McSweeney, P. L. H. 2004. Biochemistry of cheese ripening: Introduction and overview. Pages 347-360 in Cheese: Chemistry Physics and Microbiology. Volume 1. General Aspects., P. F. Fox et al., ed. Academic Press. 
Melnyk, J. P., A. Smith, C. Scott-Dupree, M. F. Marcone, and A. Hill. 2010. Identification of cheese mite species inoculated on Mimolette and Milbenkase cheese through cryogenic scanning electron microscopy. J. Dairy Sci. 93:3461-3468. https://doi.org/10.3168/ jds.2009-2937.

National Dairy Council. 2017. National Dairy Foods Research Centers and Applications Labs. Accessed Jan. 3, 2020. https://www .thinkusadairy.org/resources-and-insights/resources-and-insights/ application-and-technical-materials/national-dairy-foods-research -centers-and-applications-labs.

Ozturkoglu Budak, S., M. J. Figge, J. Houbraken, and R. P. de Vries. 2016. The diversity and evolution of microbiota in traditional Turkish Divle Cave cheese during ripening. Int. Dairy J. 58:50-53. https://doi.org/10.1016/j.idairyj.2015.09.011.

Parente, E., and T. M. Cogan. 2004. Starter Cultures: General Aspects. Pages 123-148 in Cheese: Chemistry, Physics and Microbiology, Volume 1 General Aspects. P. F. Fox et al., ed. Academic Press.

Paxson, H. 2012. The Life of Cheese: Crafting Food and Value in America. University of California Press.

Peay, K. G., P. G. Kennedy, and J. M. Talbot. 2016. Dimensions of biodiversity in the Earth mycobiome. Nat. Rev. Microbiol. 14:434447. https://doi.org/10.1038/nrmicro.2016.59.

Ropars, J., C. Cruaud, S. Lacoste, and J. Dupont. 2012. A taxonomic and ecological overview of cheese fungi. Int. J. Food Microbiol. 155:199-210. https://doi.org/10.1016/j.ijfoodmicro.2012.02.005.

Serhan, M., C. Cailliez-Grimal, F. Borges, A. M. Revol-Junelles, C. Hosri, and J. Fanni. 2009. Bacterial diversity of Darfiyeh, a Leba- nese artisanal raw goat's milk cheese. Food Microbiol. 26:645-652. https://doi.org/10.1016/j.fm.2009.04.012.

Snyder, A. B., and R. W. Worobo. 2018. The incidence and impact of microbial spoilage in the production of fruit and vegetable juices as reported by juice manufacturers. Food Control 85:144-150. https: //doi.org/10.1016/j.foodcont.2017.09.025.

Spinnler, H. E., and M. N. Leclercq-Perlat. 2007. White-mould cheese. Pages 268-283 in Cheese Problems Solved. P. L. H. McSweeney, ed. Elsevier.

Tunick, M. 2016. Texture. Pages 708-709 in The Oxford Companion to Cheese. C. W. Donnelly, ed. Oxford University Press.

Wolfe, B. E. 2016. Geotrichum candidum. Pages 311-313 in The Oxford Companion to Cheese. C. W. Donnelly, ed. Oxford University Press.

Wolfe, B. E., J. E. Button, M. Santarelli, and R. J. Dutton. 2014 Cheese rind communities provide tractable systems for in situ and in vitro studies of microbial diversity. Cell 158:422-433. https:// doi.org/10.1016/j.cell.2014.05.041.

Yeluri Jonnala, B. R., P. L. H. McSweeney, J. J. Sheehan, and P. D. Cotter. 2018. Sequencing of the cheese microbiome and its relevance to industry. Front. Microbiol. 9:1020. https://doi.org/10 $.3389 /$ fmicb.2018.01020.

\section{ORCIDS}

Megan N. Biango-Daniels ํㅏ https://orcid.org/0000-0003-1977-9424 